\title{
STABILITY INDICATING RP-HPLC METHOD FOR DETERMINATION OF GLASDEGIB IN BULK AND PHARMACEUTICAL DOSAGE FORM
}

\author{
P. Venkateswara Rao*, P. Meghana, J. Bhavana, \\ K. Bhagya Lakshmi and K. Ramya \\ Vikas College of Pharmacy, Vissannapeta, \\ Krishna District, Andhra Pradesh-521 215, India.
}

\begin{abstract}
A simple, rapid, precise, sensitive and reproducible reverse phase high performance liquid chromatography (RP-HPLC) method has been developed for the quantitative analysis of Glasdegib in pharmaceutical dosage form. Chromatographic separation of Glasdegib was achieved on Waters Alliance-e2695, by using Waters Symmetry $\mathrm{C}_{18}, 150 \mathrm{x} 4.6 \mathrm{~mm}, 3.5 \mu \mathrm{m}$ column and the mobile phase containing $0.1 \%$ TEA adjusting $\mathrm{pH}=2.5$ with OPA \& Acetonitrile in the ratio of $90: 10 \% \mathrm{v} / \mathrm{v}$. The flow rate was $0.5 \mathrm{ml} / \mathrm{min}$; detection was carried out by absorption at $268 \mathrm{~nm}$ using a photodiode array detector at ambient temperature. The number of theoretical plates and tailing factor for Glasdegib is NLT 2000 and should not more than 2 respectively. \% Relative standard deviation of peak areas of all measurements always less than 2.0. The proposed method was validated according to ICH guidelines. The method was found to be simple, economical, suitable, precise, accurate \& robust method for quantitative analysis of Glasdegib.
\end{abstract}

Keywords: Stability, HPLC and Glasdegib.

\section{INTRODUCTION}

Glasdegib is a small-molecule hedgehog signaling inhibitor selected under the group of the benzimidazoles. In early research, benzimidazoles attracted large interest as they represented a class of inhibitors with a low molecular weight, potent inhibitory activity and lacking unstable functionality. The great lipophilicity of this group of compounds brought interest to further modification. Glasdegib is chemically $1-[(2 R, 4 R)-2-(1 H-$ benzimidazol-2-yl)-1-methylpiperidin-4-yl]-3-(4cyanophenyl)urea with molecular formula $\mathrm{C}_{21} \mathrm{H}_{22} \mathrm{~N}_{6} \mathrm{O}$ shown in Fig No:1 and molecular weight is $374.448 \mathrm{~g} / \mathrm{mol}^{1,2}$. Glasdegib is a potent and selective inhibitor of the hedgehog signaling pathway that acts by binding to the smoothened (SMO) receptor. The hedgehog signalling pathway is involved in maintenance of neural and skin stem cells. In this pathway, the binding of specific ligands to the trans membrane receptor patched (PTCH1) allows the activation of the transcriptional regulators GL11, GL12 and modulation of the gene expression through SMO-mediated signaling.
The aberrant activation of the hedgehog pathway is thought to be implicated in the pathogenesis of chronic myeloid leak .As per literature survey no HPLC methods are reported for the estimation of Glasdegib., 5,7 The objective of the study is to develop accurate precise repeatable and reproducible method for simultaneous estimation of Glasdegib and to validate according to $\mathrm{ICH}$ guidelines and to perform the forced degradation studies. ${ }^{8,9,10}$<smiles>CN1CC[C@@H](NC(=O)Nc2ccc(C#N)cc2)C[C@H]1c1nc2ccccc2[nH]1</smiles>

Fig. 1: Structure of Glsdegib

MATERIALS AND METHODS 
The reference sample of glasdegib was obtained as a gift samples and the tablet containing glasdegib $25 \mathrm{mg}$ was procured from local market. Water (HPLC grade) from Rankem and acetonitrile (HPLCgrade), orthophosphoricacid (ARgrade) methanol(Rankem), triethylamine (Rankem) from Merck Limited, $0.45 \mu \mathrm{m}$ Nylon filter was from Zodiac life sciences were used.

\section{Instrumentation}

Waters HPLC 2695 system equipped with quaternary pumps, Photo Diode Array detector and Auto sampler integrated with Empower 2 Software. UV-VIS spectrophotometer, PG Instruments T60 with special bandwidth of 2 $\mathrm{mm}$ and $10 \mathrm{~mm}$ and matched quartz cells integrated with UV win 6 Software was used for measuring absorbances of glasdegib solutions, Electronics Balance-Denver $\mathrm{pH}$ meter -BVK enterprises, India UltrasonicatorBVK enterprises.

\section{Chromatographic conditions}

Waters symmetry $\mathrm{C}_{18}$ (150.x.4.6.mm, 3.5 $\mu$ ) column. Temperature was maintained ambient, mobile phase used was Acetonitrile and $0.1 \%$ TEA $(10: 90 \mathrm{v} / \mathrm{v})$ and flow rate was maintained at $0.5 \mathrm{ml} / \mathrm{min}$. Diluents used throughout the method was Water: Acetonitrile $(50: 50 \mathrm{v} / \mathrm{v})$ and the run time was 7 minutes. All the samples and mobile phase were degassed for 30 minutes and filtered by ultrasonic filtration by using $0.45 \mu \mathrm{m}$ Nylon (N66) $47 \mathrm{~mm}$ membrane filter. Detection was carried out at 268nm using PDA detector with an injection volume of $10 \mu \mathrm{L}$. By using the above optimized conditions method was developed.

\section{Preparation of Buffer \\ Buffer: (0.1\%TEA)}

Take $1 \mathrm{ml}$ of Tri ethyl amine and adjust its $\mathrm{pH}=2.5$ with Ortho Phosphoric Acid and dissolved in 1 litre of HPLC grade water. Filter through $0.45 \mu$ nylon filter.

\section{Preparation of Mobile Phase}

Mobile phase was prepared by mixing $0.1 \%$ TEA and Acetonitrile taken in the ratio 90:10. It was filtered through $0.45 \mu$ membrane filter to remove the impurities which may interfere in the final chromatogram

\section{Preparation of standard stock solution}

Accurately weigh and transfer $7 \mathrm{mg}$ of Glasdegib working standard into a $20 \mathrm{ml}$ clean dry volumetric flask add Diluents and sonic ate to dissolve it completely and make volume up to the mark with the same solvent. (Stock solution).
Further pipette $1 \mathrm{ml}$ of the above stock solutions into a $10 \mathrm{ml}$ volumetric flask and dilute up to the mark with diluents. (35ppm of Glasdegib).

\section{Sample Solution Preparation}

Accurately weighed and transfer equivalent to $7 \mathrm{mg}$ of Glasdegib sample into a $20 \mathrm{~mL}$ clean dry volumetric flask add Diluents and sonic ate it up to $30 \mathrm{mins}$ to dissolve, and centrifuge for $30 \mathrm{~min}$. to dissolve it completely and make volume up to the mark with the same solvent. Then it is filtered through 0.45 micron Injection filter (Stock solution). Further pipette $1 \mathrm{ml}$ of the above stock solutions into a $10 \mathrm{ml}$ volumetric flask and dilute up to the mark with diluents. (35ppm of Glasdegib).

\section{METHOD VALIDATION \\ Specificity}

Specificity of an analytical method is ability to measure specifically the analyte of interest without interference from blank and known impurities. For this purpose blank chromatogram, standard chromatogram and sample chromatogram were recorded. The chromatogram of blank shows no response at the retention times of drugs which confirms the response of drug was specific

\section{SYSTEM SUITABILITY}

Tailing factor for the peak due to Glasdegib in Standard solution should not be more than 2.0 Theoretical plates for the Glasdegib peak in Standard solution should not be less than 2000.

\section{Formula for Assay}

$$
\begin{gathered}
\% \text { Assay }=\frac{A T}{A S} * \frac{W S}{D S} * \frac{D T}{W T} * \frac{\text { Average weight }}{\text { Label Claim }} \\
* \frac{P}{100} * 100
\end{gathered}
$$

Where

$\mathrm{AT}=$ average area counts of test (sample) preparation.

$A S=$ average area counts of standard preparation.

$\mathrm{WS}=$ Weight of working standard taken in $\mathrm{mg}$.

$\mathrm{DS}=$ Dilution of working standard in $\mathrm{ml}$.

$\mathrm{DT}=$ Dilution of test (sample) in $\mathrm{ml}$.

$\mathrm{WT}=$ Weight of test (sample) taken in $\mathrm{mg}$.

$\mathrm{P}=$ Percentage purity of working standard

$\mathrm{LC}=$ Label Claim $\mathrm{mg} / \mathrm{ml}$.

\section{Linearity}

The linearity of the proposed method was determined by quantitative dilution of the standard solution of glasdegib to obtain solution in concentration range of $3.50 \mu \mathrm{g} / \mathrm{ml}-$ 
$52.50 \mu \mathrm{g} / \mathrm{ml}$. A graph of peak area versus concentration in $\mu \mathrm{g} / \mathrm{ml}$ was plotted for the drug. The slope intercept and correlation coefficient of regression line.

\section{Limit of detection (LOD) and limit of quantification (LOQ)}

The LOD and LOQ represent the concentration of analyte that would yield to signal-to-noise ratio of 3 for LOD and 10 for LOQ. LOD and LOQ were calculated using following formula,

$$
\begin{aligned}
& L O D=3.3 \sigma / S \\
& L O Q=10 \sigma / S
\end{aligned}
$$

where, $\sigma=$ standard deviation of response (peak area) and

$\mathrm{S}=$ average of slope of the calibration

\section{Method precision}

In method precision, a homogenous sample of single batch should be analyzed 6 times. This indicates whether a method is giving constant results for a single batch. In this analyze the sample six times and calculate the \% RSD

The precision of the instrument was checked by repeatedly injecting $(n=6)$ solutions of 35ppm of Glasdegib).

\section{System precision}

System precision is checked by using standard chemical substance to ensure that the analytical system is working properly. In this peak area and \% of drug of six determinations is measured and \% RSD should be calculated.

\section{Accuracy}

The accuracy of this method was performed at three different levels $(50 \%, 100 \%, 150 \%)$, by the addition of a known amount of standard to the sample at each level. Each level was repeated three times $(n=3)$.

\section{Robustness}

Robustness is the measure of optimized method capacity to remain unaffected by small, but deliberate variations in method parameters such as mobile phase flow rate $( \pm 0.2 \mathrm{~mL} / \mathrm{min})$, wavelength $\mathrm{nm}( \pm 1 \mathrm{~nm})$, and column oven temperature $\left( \pm 1^{\circ} \mathrm{C}\right)$.

\section{Solution Stability}

The solution stability of glasdegib in diluents was determined by storing sample

Solution in tightly capped volumetric flask at room temperature for $24 \mathrm{hrs}$. The amount of Glasdegib was measured at different time intervals like 6, 12, 18 and $24 \mathrm{hrs}$ and results obtained were compared with freshly prepared of glasdegib solution.

\section{RESULTS AND DISCUSSION Chromatographic conditions}

Waters symmetry $\mathrm{C}_{18} \quad(150 \times \mathrm{x}$ 4.6.mm, $3.5 \mu$ particle size) column. Temperature was maintained ambient, mobile phase used was : Acetonitrile and0.1\%TEA $(10: 90 \mathrm{v} / \mathrm{v})$ and flow rate was maintained at $0.5 \mathrm{ml} / \mathrm{min}$. Diluent used throughout the method was Water: Acetonitrile $(50: 50 \mathrm{v} / \mathrm{v})$ and the run time was 7 mins. All the samples and mobile phase were degassed for 30 mins and filtered by ultrasonic filtration by using $0.45 \mu \mathrm{m}$ Nylon (N66) $47 \mathrm{~mm}$ membrane filter. Detection was carried out at 268nmnm using PDA detector with an injection volume of $10 \mu \mathrm{L}$. By using the above optimized conditions method was developed .Shown in Fig. 2 and Table 1.

\section{Specificity}

Specificity of an analytical method is ability to measure specifically the analyte of interest without interference from blank and known impurities. For this purpose blank chromatogram, standard chromatogram and sample chromatogram were recorded. The chromatogram of blank shows no response at the retention times of drugs which confirms the response of drug was specific.

\section{Linearity}

The linearity of the proposed method was determined by quantitative dilution of the standard solution of glasdegib to obtain solution in concentration range of $3.50 \mu \mathrm{g} / \mathrm{ml}-$ $52.50 \mu \mathrm{g} / \mathrm{ml}$. A graph of peak area versus concentration in $\mu \mathrm{g} / \mathrm{ml}$ was plotted for the drug. The slope, intercept, and correlation coefficient of regression line were determined. Shown in Table 2.

\section{Method precision}

In method precision, a homogenous sample of single batch should be analyzed 6 times. This indicates whether a method is giving constant results for a single batch. In this analyze the sample six times and calculate the \% RSD

The precision of the instrument was checked by repeatedly injecting $(n=6)$.solutions of $35 p p m$ of Glasdegib). Table 3.

\section{System precision}

System precision was determined by measuring the peak area of six replicate injections of standard solution. The value of $\%$ RSD was found to be $<2$, which ensure the analytical system is working properly. The results of system precision are tabulated in Table No:4. 


\section{Accuracy}

The accuracy of this method was determined by calculating percent recovery of glasdegib in formulation at three different levels $(50 \%$, $100 \%$, and $150 \%$ ). The $\%$ recovery obtained was found to be in the range of 100.36 to $100.54 \%$. The accepted limits of mean recovery is $100.25 \%$ and obtained results were within the acceptable range, which indicate recovery values were good, affirming the accuracy of the developed method. The results are summarized in Table 5.

\section{Robustness}

The method was found to be robust when minor changes were made in optimized chromatographic conditions such as oven temperature $\left( \pm 5^{\circ} \mathrm{C}\right)$, mobile phase flow rate $( \pm 0.1 \mathrm{~mL} / \mathrm{min})$, and ratio of mobile phase
$( \pm 5 \mathrm{~mL})$. It was observed that there was no marked change in analytical data of the drugs which indicates good reliability during normal usage. The results are shown in Table 6 .

\section{Solution Stability}

The solution stability of glasdegib in diluents was determined by storing sample solution in tightly capped volumetric flask at room temperature for $24 \mathrm{hrs}$. The amount of glasdegib was measured at different time intervals like 6, 12, 18 and $24 \mathrm{hrs}$ and results obtained were compared with freshly prepared of glasdegib solution

Acceptance Criteria: The \%RSD values for the assay of the solution stability experiments were calculated and should not more than $2.0 \%$.

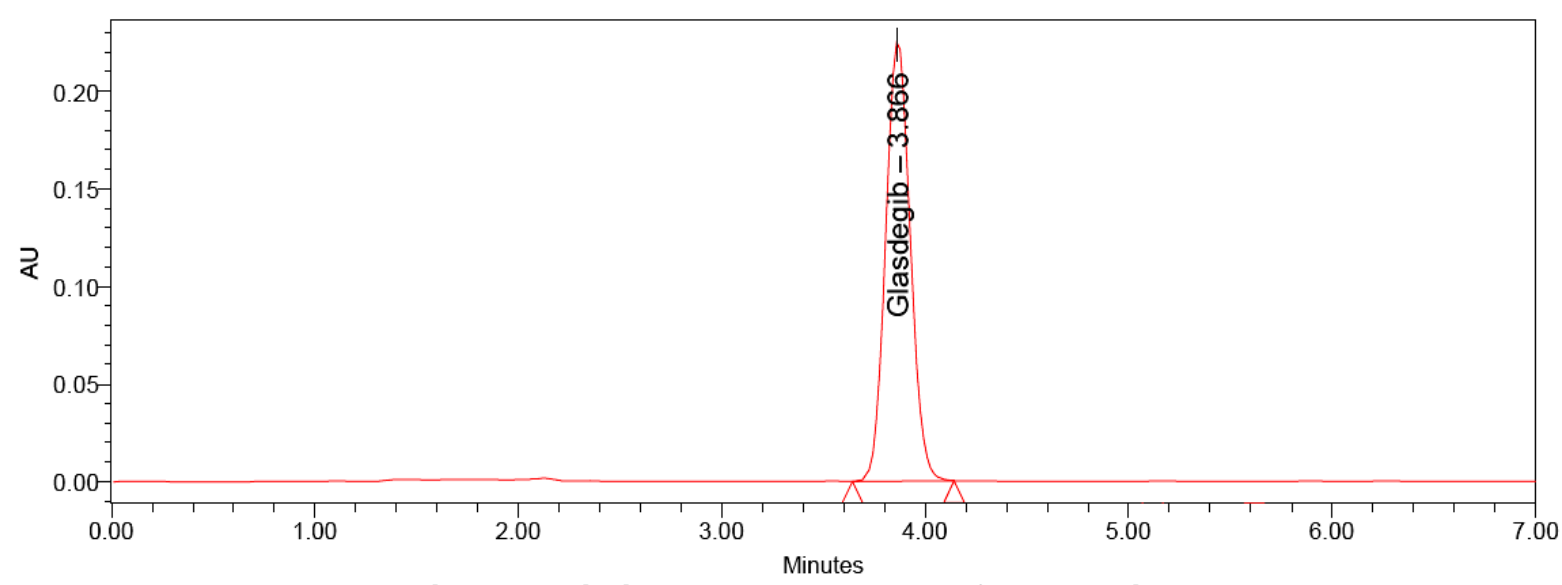

Fig. 2: Optimized chromatogram of Glasdegib

Table 1: Optimized Chromatographic conditions of Glasdegib

\begin{tabular}{|c|c|}
\hline Parameters & Observation \\
\hline Instrument used & Waters HPLC with auto sampler and PDA detector. \\
\hline Injection volume & $10 \mu \mathrm{L}$ \\
\hline Mobile Phase & Acetonitrile and 0.1\% TEA of $\mathrm{pH}=2.5$ adjusted with OPA 10:90 \\
\hline Column & Waters Symmetry $\mathrm{C}_{18,150 \times 4.6 \mathrm{~mm}, 3.5 \mu}$ \\
\hline Detection Wave Length & $268 \mathrm{~nm}$ \\
\hline Flow Rate & $0.5 \mathrm{ml} / \mathrm{min}$ \\
\hline Runtime & $7 \mathrm{~min}$ \\
\hline Temperature & Ambient $\left(25^{\circ} \mathrm{C}\right)$ \\
\hline Mode of separation & Isocratic mode \\
\hline
\end{tabular}




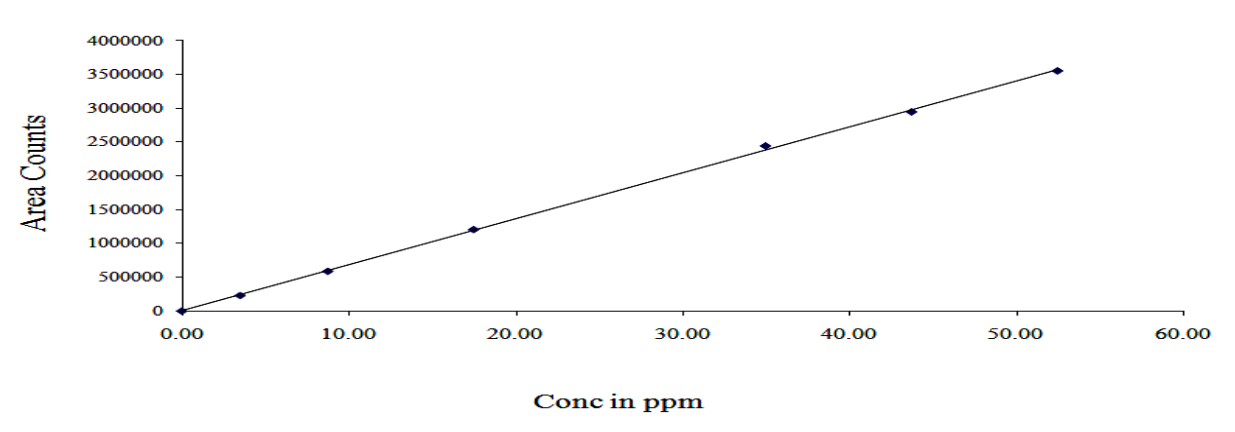

Fig. 3: Calibration curve of Glasdegib

Table 2: Results of linearity of Glasdegib

\begin{tabular}{|c|c|c|}
\hline \multirow{2}{*}{ S.NO } & \multicolumn{2}{|c|}{ Glasdegib } \\
\cline { 2 - 3 } & Conc. $\boldsymbol{\mu \mathrm { g } / \mathbf { m l } )}$ & Peak area \\
\hline 1 & 3.50 & 229582 \\
\hline 2 & 8.75 & 587786 \\
\hline 3 & 17.50 & 1207676 \\
\hline 4 & 35.00 & 2447475 \\
\hline 5 & 43.75 & 2951689 \\
\hline 6 & 52.50 & 3559389 \\
\hline $\begin{array}{c}\text { Regression } \\
\text { equation }\end{array}$ & \multicolumn{2}{|c|}{$\mathrm{y}=68070 \mathrm{x}+3461$} \\
\hline Slope & \multicolumn{2}{|c|}{68070.61} \\
\hline Intercept & \multicolumn{2}{|c|}{0.99977} \\
\hline $\mathbf{R}^{2}$ & \multicolumn{2}{|c}{} \\
\hline
\end{tabular}

Table 3: Method Precision of Glasdegib

\begin{tabular}{|c|c|}
\hline Injection & Area for Glasdegib \\
\hline Injection-1 & 2416385 \\
\hline Injection-2 & 2416795 \\
\hline Injection-3 & 2418957 \\
\hline Injection-4 & 2463125 \\
\hline Injection-5 & 2415316 \\
\hline Injection-6 & 2417854 \\
\hline Average & 2424738.7 \\
\hline Standard Deviation & 18846.799 \\
\hline \%RSD & 0.78 \\
\hline
\end{tabular}

Table 4: System Precision of Glasdegib

\begin{tabular}{|c|c|}
\hline Injection & Area for Glasdegib \\
\hline Injection-1 & 2413679 \\
\hline Injection-2 & 2413255 \\
\hline Injection-3 & 2468957 \\
\hline Injection-4 & 2495875 \\
\hline Injection-5 & 2469856 \\
\hline Injection-6 & 2413625 \\
\hline Average & 2445874.7 \\
\hline Standard Deviation & 36738.471 \\
\hline \%RSD & 1.7 \\
\hline
\end{tabular}


Table 5: Accuracy results of Glasdegib

\begin{tabular}{|c|c|c|c|c|c|}
\hline $\begin{array}{c}\text { \%Concentration(at } \\
\text { specification Level) }\end{array}$ & Area & $\begin{array}{c}\text { Amount of } \\
\text { sample } \\
\text { Added } \\
\text { (mg) }\end{array}$ & $\begin{array}{c}\text { Amount } \\
\text { Found } \\
\text { (mg) }\end{array}$ & \% Recovery & Mean Recovery \\
\hline $50 \%$ & 1364852 & 25.1 & 17.5 & 100.36 & \multirow{2}{*}{100.25} \\
\hline $100 \%$ & 2463157 & 50.1 & 35 & 99.95 & \\
\hline $150 \%$ & 3746275 & 75.2 & 52.5 & 100.54 & \\
\hline
\end{tabular}

Table 6: Robustness results of Glasdegib

\begin{tabular}{|c|c|c|c|c|c|}
\hline \multirow{2}{*}{ Parameter } & \multicolumn{5}{|c|}{ Glasdegib } \\
\cline { 2 - 6 } & Condition & $\begin{array}{c}\text { Retention } \\
\text { time(min) }\end{array}$ & Peak area & Tailing & Plate count \\
\hline \multirow{2}{*}{$\begin{array}{c}\text { Flow rate } \\
\text { Change } \\
\text { (ml/min) }\end{array}$} & Less flow $(0.4 \mathrm{ml})$ & 4.975 & 2315648 & 1.04 & 3579 \\
\cline { 2 - 6 } & Actual(0.5ml) & 3.845 & 2463157 & 1.04 & 3545 \\
\cline { 2 - 6 } & More flow(0.6ml) & 3.161 & 2567841 & 1.05 & 3492 \\
\hline \multirow{2}{*}{$\begin{array}{c}\text { Organic Phase } \\
\text { change }\end{array}$} & Less Org (9:91) & 4.876 & 2369854 & 1.11 & 3493 \\
\cline { 2 - 6 } & Actual(10:90) & 3.847 & 2463975 & 1.12 & 3528 \\
\cline { 2 - 6 } & More Org(11:89) & 3.068 & 2563145 & 1.05 & 3496 \\
\hline
\end{tabular}

\section{CONCLUSION}

The developed HPLC method for the estimation of selected drug is simple, rapid, accurate, precise, robust and economical. The mobile phase and solvents are simple to prepare and economical, reliable, sensitive and less time consuming. The sample recoveries were in good agreement with their respective label claims and they suggested non interference of formulation excipients in the estimation and can be used in laboratories for the routine analysis of selected drugs. Since the system validation parameters of HPLC method used for estimation of selected drug in pure and have shown satisfactory, accurate and reproducible results (without any interference of excipients) as well, it is deduced that the simple and short proposed methods be most useful for analysis purpose. The present work concluded that stability indicating assay method by RP-HPLC was simple, accurate, precise, and specific and has no interference with the placebo and degradation products. Hence these can be used for routine analysis of Glasdegib.

\section{REFERENCES}

1. Drug bank. Com. Drug created on October 20, 2016 15:07 / Updated on December 02, 2019 09:15. https://www.drugbank.ca/drugs/DB11978.

2. Munchhof MJ, Li Q, Shavnya A, Borzillo GV, Boyden TL, Jones CS, LaGreca SD, Martinez-Alsina L, Patel N, Pelletier K, Reiter LA, Robbins MD and Tkalcevic GT. a Potent and Orally Bio available Inhibitor of Smoothened. ACS Med Chem Lett. $2011 ; 21 ; 3(2): 106-111$.
3. Irvine DA and Copland M. Targeting hedgehog in hematologic malignancy. Blood. 2012;119(10):2196-2204.

4. Lam JL, Vaz A, Hee B, Liang Y, Yang $X$ and Shaik MN. Metabolism, excretion and pharmacokinetics of glasdegib in healthy volunteers following oral administration. Xenobiotica. 2017;47(12):1064-1076.

5. Justine L Lam, Alfin Vaz, Brian Hee, Yali Liang and Xin Yang M. Naveed Shaik Xenobiotica. The metabolism, excretion and pharmacokinetics of glasdegib -were investigated following administration of a single oral dose of $100 \mathrm{mg} / 100 \mu \mathrm{Ci}$. 2017;47(12):1-12.

6. Naveed SK. inhibitor on the pharmacokinetics of glasdegib in healthy volunteers a randomized phase $I$. "Evaluation of the effects of formulation, food, or a proton-pump study. Cancer chemotherapy and pharmacology. 2019;83(3):463-472.

7. Minimi and Yosuke. Phase I study of glasdegib an oral smoothened inhibitor, in Japanese patients with select hematologic malignancies. Cancer science. 2017;108(8):1628-1633.

8. Chan CC. Analytical Method Validation: Principles and Practices, in Pharmaceutical Manufacturing Handbook: Regulations and Quality. Edited by Shyne Cox Gad. John Wily and Sons. 2008.

9. ICH Q2A. Text on Validation of Analytical Procedures. Geneva Q2A, in 2005. Incorporated in Q2 (R1). 1994.

10. ICH Q2B. Validation of Analytical Procedures: Methodology. Geneva Q2B in 2005 incorporated in Q2 (R1). 1996. 